\title{
The Discussion of Life-teaching Method about C Language under the Innovative Forms
}

\author{
Yan-ling ZHOU \\ Department of Computer Science and Technology \\ Hefei University \\ Hefei,China \\ zhouyanling1006@163.com
}

\begin{abstract}
Theory comes from life, return to life again. In view of the problems existing in the freshman about learning $\mathrm{C}$ language in the applied colleges, life-case teaching methods are applied to teaching $\mathrm{C}$-language program. It can make students learn $\mathrm{C}$ language in a tangible world and find the beauty of the $\mathrm{C}$ language in the life. It has made the students' ability to use knowledge to solve practical problems, at the same time, it has guided and inspired the students to find the problems, analyze the problems and solve the problem. In addition, it can cultivate students' innovative thinking and innovative ability. It complies with the requirement of era development.
\end{abstract}

Keywords—C language; life teaching; applied colleges

\section{INTRODUCTION}

$\mathrm{C}$ language has the characteristics of high-level language, the ability to directly manipulate computer hardware, rich flexible control and data structure, concise and effective expressions, clear program structure and good portability. These advantages make the $\mathrm{C}$ language become the first professional-compulsory program language in college computer [1]. Currently, most programming-language teaching methods are on the basis of the knowledge structure, the classroom teaching is given priority to injection of teaching that teaching method make students only copy and imitate the example code, so the student cannot flexible use of knowledge to solve practical problems by computer. Although the support of multimedia, most teachers still use the traditional teaching method to teach the $\mathrm{C}$ programming Language in the classroom teaching. In the teaching process, the syntax is the important, the each knowledge point is independent, especially the basic data types, basic operation, simple input and output, all kinds of operators, program control structures, etc. So they are out of the overall structure of the C language and the teaching method will only make the students to remember grammar without programming ideas. Students didn't obtain the ability to understanding, analyzing and solving practical problems. If the students do so in the long term, they will lose their interest [2]. In order to adapt to today's social innovation, our teacher must improve their teaching ability from a variety of ways, guide the student to go to like a course, and the more important thing is to cultivate the student to be with the ability and consciousness to apply the learned knowledge to innovate. Because the theory comes from life, returns to life again.

\section{THE IMPORTANCE OF C LANGUAGE AND THE EXISTING TEACHING PROBLEM}

A. The Importance of C Language

The importance of the $\mathrm{C}$ language is shown in the following aspects:

1) $\mathrm{C}$ is the most basic and important programming language in programming languages, In the course system, it is in the predominance and foundational position. It is an important technology and tool for learning the follow-up courses.

2) C language learning can not only make the student to obtain the most basic programming skills, to cultivate students' thinking ability based on computer, but also cultivate students to have the ability to program design to solve practical problems.

3) $\mathrm{C}$ is closely related to hardware, and many operating systems are developed by $\mathrm{C}$, such as Unix systems, Windows systems, Linux systems, etc. Some applications are also developed in $\mathrm{C}$, so the $\mathrm{C}$ language is very powerful.

First, confirm that you have the correct template for your paper size. This template has been tailored for output on the A4 paper size. If you are using US letter-sized paper, please close this file and download the file "MSW_USltr_format".

\section{B. The Problems in C Language Teaching}

The main problems of $\mathrm{C}$ language in the teaching are in the following aspects: 
1) $\mathrm{C}$ is the first course in programming language for freshmen. In the computer science of hefei college, the opening time of the $\mathrm{C}$ language is the first semester in the freshman year, almost all the courses start at the same time, so, for the freshmen, $\mathrm{C}$ language learning is to start from zero foundation, they had not learned any knowledge related to the computer before [3] .C language as a computer language, the logic is very strong, students must be able to use the C language grammar to solve practical problems by computer. At the same time, the freshmen are still at the adaptation of university. As a result, $\mathrm{C}$ language has a certain degree of difficulty compared with the other courses.

2) $\mathrm{C}$ is a process-oriented programming language, and in practice, functions are very important in the $\mathrm{C}$ language program . In the $\mathrm{C}$ language teaching, we found the students tended to like in a main function main () to write all the code, not willing to lachieve the special function through the custom function. Therefore, students are lack of ability of decomposition function module. In fact, when writing the first $\mathrm{C}$ language program, we use the input and output functions, the function is always present.

3) In the $C$ language experiment, the student lacks the ability to debug the program. When the program compiles the error, the student's first reaction is to find the teacher to solve the problem; he does not take the initiative to find the attitude of the problem, but not to analyze the problem to solve the problem. Therefore, in the $\mathrm{C}$ language teaching process, students should be able to develop the ability to read the program.

4) $\mathrm{C}$ language is a programming language, and learning $\mathrm{C}$ language is the purpose of being able to solve the practical problems in life through the computer. However, students are more confused about learning $\mathrm{C}$ language; do not know what the $\mathrm{C}$ language can do in the end. Therefore, students are confused about learning $\mathrm{C}$, and don't know what $\mathrm{C}$ can do. Therefore, in the $\mathrm{C}$ language teaching, the teacher must put the actual problems in life as the case in the course of the $\mathrm{C}$ language teaching, and cannot be read from the book. To get students to find problems in life, they can solve problems in C, so they have a deep grasp of the C language of [4].

\section{C LANGUAGE IN LIFE}

\section{A. Header files and system functions}

In the process of C-language teaching, the relationship between the header file and the system function can be likened to a toolbox and tool. For example, the first simple program in the first class of $\mathrm{C}$ language is shown in figure 1.

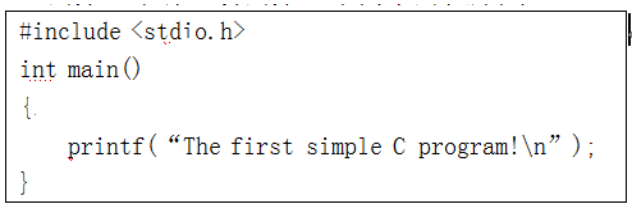

Fig. 1. First $\mathrm{C}$ program

In the process of $\mathrm{C}$ language teaching, teachers can use the object in life to visualize teaching for example regarding $\mathrm{C}$ language header file as a toolbox, function as tools. Before using tools, you need to get equipped with the tool kit together.

The main function is the mouth of program, but only one mouth. How many words the mouth says will use \{\} to define, and \{\} is the program's code inside functions. The toolbox is easier to remember than the header files. The toolbox has a name, the name of the toolbox is the name of the header file, and the name of the tool in the toolbox is the name of the function. A toolbox can contain many tools, so a header file contains multiple functions. When students slowly understanding the C language, we can put the toolbox renamed header files, renamed the tool as function in the later teaching.

\section{B. Variables and memory}

In the process of the C-language teaching, we can compare the relation between variables and memory with the relationship between the students and the dormitory. When the teachers explain the defining variables, they often use the following simple codes as shown in figure 2.

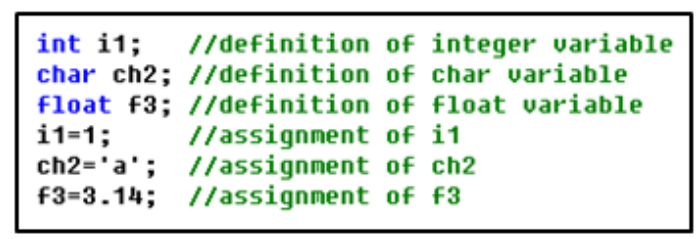

Fig. 2. Definition and assignment of the variable 
In the $\mathrm{C}$ language, the variables include the basic knowledge point such as the name of the variable, the type of the variable, the declaration of the variable, the assignment of the variable in the variable's life cycle. Before the teachers introduce variables, they can let the students think carefully about the relationship between the students and the dormitory. Teachers can inspire students to think in four areas including timeliness, order, variability and diversity.

\section{1) Timeliness}

In the student -dormitory relationship, the maximum time of an undergraduate can live in a dormitory is four years under normal conditions. In the relationship of variables - memory, the survival of variable in memory is called life cycle. According to the different life cycle of variables, the variables can be divided into local variables and global variables. The life cycle of variable is determined according to the variable's scope \{\} .

\section{2) Ordinal}

In the student-dormitory relationship, the ordinal reflects that first dormitory assigning and last checking in. Each dormitory has their own number and each bed has their own bed number. In the variable - memory relationship, the variable is declared firstly and then assigned. The purpose of the variable declaration is the allocation of memory space. The purpose of the variable assigning is to change the contents of the memory space. The number of bed and dormitory is according to the name of the variable, and the first character of the variable name t must be the letter which is different from the number of dormitory.

\section{3) Variability}

In the student-dormitory relationship, the dormitory location remains the same, but the name of the dormitory can be changed, and the person in the dormitory bed can also change. In a variable - memory relationship, the memory's spatial location is unchanged, but the name of the variable can be changed, and the contents of the memory space can be changed by the value of the variable.

\section{4) Diversity}

In the student-dormitory relationship, there are two kinds of dormitories including male dormitory and female dormitory. Boys and girls are two different sexes. The boys are in the male dormitory, the female is in the female dormitory. In the variablememory relationship, the type of the variable can be integer, character, float and so on. When allocating memory for the variable, the different types of variables are distributed memory space corresponding to the type size. The size of the integer variables allocated memory space of the size of 2 bytes usually. And the characters variable are allocated memory space size of 1 byte, float type variable are allocated memory space of four bytes, etc.

To sum up, through the interpretation of the students-dormitory relationship, students will naturally receive and understand the variables involved in the $\mathrm{C}$ language knowledge and they can feel the charm of the $\mathrm{C}$ language from life.

\section{Control structure}

In the process of $\mathrm{C}$ language teaching, we can analyze the university curriculum structure relations in detail, which can lead control structure of the $\mathrm{C}$ programming language. In $\mathrm{C}$ programming language, the syntax format of three kinds of control structures is shown in figure 3.

\begin{tabular}{|c|c|c|c|c|}
\hline $\begin{array}{l}\text { sequential } \\
\text { structure }\end{array}$ & $\begin{array}{l}\text { selective } \\
\text { structure }\end{array}$ & \multicolumn{3}{|c|}{ loop structure } \\
\hline $\begin{array}{l}\text { statement } 1 ; \\
\text { statement } 2 ; \\
\text { statement } 3 ; \\
\text {........ }\end{array}$ & $\begin{array}{l}\text { if (condition) } \\
\{ \\
\text { statements; } \\
\text { else } \\
\{ \\
\text { statements; }\end{array}$ & $\begin{array}{l}\text { while(conditio } \\
\text { n) } \\
\left\{\begin{array}{l}\text { foop } \\
\text { statement; } \\
\}\end{array}\right.\end{array}$ & $\begin{array}{l}\text { do } \\
\{ \\
\text { loop } \\
\text { statements; } \\
\text { \}while(conditi } \\
\text { on) }\end{array}$ & $\begin{array}{l}\text { for(; condition; }) \\
\left\{\begin{array}{l}\text { loop } \\
\text { statements; } \\
\}\end{array}\right.\end{array}$ \\
\hline
\end{tabular}

Fig. 3. Control structure in $\mathrm{C}$ language

The control results of $\mathrm{C}$ language are divided into three types such as the sequential structure, selective structure and Loop structure. The three structures are fully embodied in the curriculum.

\section{1) Sequential structure}

The sequential structure of curriculum reflects that first morning class and then afternoon class every day, first Monday class, and then Tuesday class, Wednesday class, Thursday class, final Friday class. The inner structure of curriculum fully reflects the sequential-structure relationship of first up and after down, first left and after right. In the control structure of $\mathrm{C}$ language, the executing rule of the sequence-structure program is first up and after down, first left and after right.

\section{2) Selective structure or branching structure}

The selective structure of curriculum reflects that students can take many courses in one semester but only take one course at a given time. Each class has different curriculum. The students take their courses according to the class and time. In the control 
structure of $\mathrm{C}$ language, the executing rule of selective structure is first judging the condition and then executing the program. When talking about the branching structure, the conditional expressions are critical. When talking about the conditional expressions, we can explain the relational operators and logical operators. Thus it can not only let the students realize the importance of conditional statements, but also make the students to learn the cautions and using methods of various operators. It is better to learn from life's practical problems than from book alone.

\section{3) Loop structure}

The loop structure of curriculum reflects that the students' class must be carried out in accordance with the arrangement of curriculum. The same curriculum is performed every week in spite of the different time. If the semester is finished, the curriculum content is not carried out. By analyzing, we can see that the repeating content is curriculum. The period is from the beginning of the term to the end of the term. In the control structure of $\mathrm{C}$ language, the executing rule of the loop structure is that repeating executing the loop statement if the loop condition is satisfying. Here the loop variable can change according to certain rule, the loop condition decides to terminate the loop, the loop body statement can be repeated to execute if the condition is satisfied.

To sum up, the explanation of the sequential structure, selective structure and loop structure of control structure and combined with curriculum of the University will make students feel the knowledge really comes from life and returns to life.

\section{SUMMARY}

C language teaching is contact with the students' practical lives, which can make students feel the real life world is a world full of knowledge. We should guide the student to apply the theoretical knowledge to solve practical problems of life. In the process of teaching, the students are studying in an interactive and developing learning environment. Thus the teaching effect is much better than the traditional conventional teaching way. The teaching method contacting with life has inspired the students' learning interest in the better learning atmosphere, improved the students' ability to find, analyze and solve practical problems. Finally, the students' innovative consciousness and innovative applying ability have been further developed.

\section{ACKNOWLEDGMENT}

This paper is supported by Natural science fund project from the department of education of Anhui province (KJ2016A609).

\section{REFERENCES}

[1] James M.Copper, Susan Goldman etc. Classroom Teaching Skills[M]. Houghton Mifflin Company. 2002:196-212.

[2] M. Abdullah-Al-Wadud. A Procedural Way of Teaching Procedural Programming Languang [J].International Journal of Education and Learning Systems,2016,16(1):114-117.

[3] NikolaosS.Papaspyrou, StathisZachos. Teaching Programming through Problem Solving: The Role of the Programming Language[C] . Proceedings of the 2013 Federated Conference on Computer Science and Information Systems, 2013:1533-1536.

[4] BasseyIsong. A Methodology for Teaching Computer Programming: first year students' perspective [J]. I.J.Modern Education and Computer Science, 2014,68(2): 15-21. 